\title{
Predictors of postconcussion syndrome after sports-related concussion in young athletes: a matched case-control study
}

\author{
Clinton D. Morgan, BA, ${ }^{1}$ Scott L. Zuckerman, MD, ${ }^{1}$ Young M. Lee, BSPH, ${ }^{1}$ Lauren King, MSN, ${ }^{2}$ \\ Susan Beaird, DNP, ${ }^{2}$ Allen K. Sills, MD, ${ }^{1}$ and Gary S. Solomon, PhD ${ }^{1}$ \\ 1Department of Neurological Surgery, Vanderbilt Sports Concussion Center, and 2Division of Pediatric Neurology, Vanderbilt \\ University School of Medicine, Nashville, Tennessee
}

\begin{abstract}
OBJECT Sport-related concussion (SRC) is a major public health problem. Approximately $90 \%$ of SRCs in high school athletes are transient; symptoms recover to baseline within 1 week. However, a small percentage of patients remain symptomatic several months after injury, with a condition known as postconcussion syndrome (PCS). The authors aimed to identify risk factors for PCS development in a cohort of exclusively young athletes (9-18 years of age) who sustained SRCs while playing a sport.

METHODS The authors conducted a retrospective case-control study by using the Vanderbilt Sports Concussion Clinic database. They identified 40 patients with PCS and matched them by age at injury and sex to SRC control patients (1 PCS to 2 control). PCS patients were those experiencing persistent symptoms at 3 months after an SRC. Control patients were those with documented resolution of symptoms within 3 weeks of an SRC. Data were collected in 4 categories: 1) demographic variables; 2) key medical, psychiatric, and family history; 3) acute-phase postinjury symptoms (at 0-24 hours); and 4) subacute-phase postinjury features (at 0-3 weeks). The chi-square Fisher exact test was used to assess categorical variables, and the Mann-Whitney U-test was used to evaluate continuous variables. Forward stepwise regression models $\left(P_{i n}=0.05, P_{\text {out }}=0.10\right)$ were used to identify variables associated with PCS.
\end{abstract}

RESULTS PCS patients were more likely than control patients to have a concussion history $(p=0.010)$, premorbid mood disorders $(p=0.002)$, other psychiatric illness $(p=0.039)$, or significant life stressors $(p=0.036)$. Other factors that increased the likelihood of PCS development were a family history of mood disorders, other psychiatric illness, and migraine. Development of PCS was not predicted by race, insurance status, body mass index, sport, helmet use, medication use, and type of symptom endorsement. A final logistic regression analysis of candidate variables showed PCS to be predicted by a history of concussion (OR $1.8,95 \% \mathrm{Cl} 1.1-2.8, p=0.016)$, preinjury mood disorders $(\mathrm{OR} 17.9,95 \% \mathrm{Cl}$ $2.9-113.0, p=0.002$ ), family history of mood disorders (OR 3.1, $95 \% \mathrm{Cl} 1.1-8.5, \mathrm{p}=0.026)$, and delayed symptom onset (OR 20.7, 95\% Cl 3.2-132.0, $\mathrm{p}<0.001$ ).

CONCLUSIONS In this age- and sex-matched case-control study of risk factors for PCS among youth with SRC, risk for development of PCS was higher in those with a personal and/or family history of mood disorders, other psychiatric illness, and migraine. These findings highlight the unique nature of SRC in youth. For this population, providers must recognize the value of establishing the baseline health and psychiatric status of children and their primary caregivers with regard to symptom reporting and recovery expectations.

In addition, delayed symptom onset was an unexpected but strong risk factor for PCS in this cohort. Delayed symptoms could potentially result in late removal from play, rest, and care by qualified health care professionals. Taken together, these results may help practitioners identify young athletes with concussion who are at a greater danger for PCS and inform larger prospective studies for validation of risk factors from this cohort.

http://thejns.org/doi/abs/10.3171/2014.10.PEDS14356

KEY WORDS concussion; sports; mild traumatic brain injury; ImPACT; postconcussion syndrome; trauma

ABBREVIATIONS BMI = body mass index; $\mathrm{mTBI}=$ mild traumatic brain injury; $\mathrm{PCS}=$ postconcussion syndrome; $\mathrm{PCSS}=$ Post-Concussion Symptom Scale; $\mathrm{SRC}=$ sportrelated concussion; VSCC $=$ Vanderbilt Sports Concussion Center.

SUBMITTED July 18, 2014. ACCEPTED October 31, 2014.

INCLUDE WHEN CITING Published online March 6, 2015; DOI: 10.3171/2014.10.PEDS14356.

DISCLOSURE Support for this study came from an unrestricted educational grant from Rawlings. Dr. Solomon is a consultant for ImPACT, Nashville Predators, and Tennessee Titans. 
$\mathrm{E}$ $\mathrm{ACH}$ year in the United States, an estimated 136,000 sports-related concussions (SRCs) occur in young people. ${ }^{49}$ Recognition of the burden of SRC among children and adolescents has provoked a wave of study into its prevention and treatment. Concussion incidence peaks among those 9 to 22 years of age, when school and group athletics are most popular. ${ }^{70}$ At least $25 \%$ of concussions in children seen at emergency departments are sports related.

Most SRC symptoms are transient. ${ }^{11}$ In fact, for more than $90 \%$ of high school athletes, symptoms recover to baseline within 1 week after SRC. ${ }^{23,24,30,42,44,46}$ However, for a minority of athletes, recovery is protracted, in the form of what has been termed postconcussion syndrome (PCS). ${ }^{49,51}$ Classic features of PCS can be grouped into 4 symptom domains: somatic, cognitive, sleep, and emotional (Table 1). ${ }^{10,37}$ For young athletes who experience postconcussion symptoms for months, the ramifications can be devastating. Young athletes with PCS can demonstrate prominent exercise intolerance, neurocognitive dysfunction, reaction time variability, and decreased working memory. ${ }^{12,19,53}$ The literature indicates that the percentage of young athletes in whom PCS develops after SRC varies from 1.5\% to $15 \%, 3,40,49,69$ This wide range of PCS incidence is probably attributable to variation in the population studied, the time frame used for making the diagnosis, and measurable risk factors. Numerous studies have attempted to identify predictive factors for PCS: For example, in samples of high school and collegiate athletes, an increasing number of previous concussions has been found to be a risk factor for PCS. ${ }^{23,57,62}$ Also associated with a higher likelihood of PCS after mild traumatic brain injury (mTBI) in youth are immediate postinjury amnesia, loss of consciousness, confusion, migraine headache, photophobia, phonophobia, and poor cognition. . $^{15,16,33,35,38,43}$ However, even these findings have been disputed; the association depends on whether the mTBI was sport related. ${ }^{50}$

Demographic risk factors have also been studied. Young, female athletes have been shown to have a higher number of PCS symptoms after mTBI, report more migraines, and demonstrate more pronounced cognitive deficits. ${ }^{10,66}$ Preinjury psychosocial context is also thought to play a role. Predictors of PCS after mTBI in children are increasing parental anxiety, parental financial resources, preexisting learning difficulties, psychiatric illness, family stressors, symptom attribution, and a child's decreasing health-related quality of life..$^{56,58,70}$

Although the literature is replete with studies that have evaluated risk factors for PCS in a general mTBI popula- tion, to our knowledge, there is a dearth of research reporting exclusively on SRCs among youth. ${ }^{5,6,56,58,63,69,70}$ The goal of our study was to determine which risk factors predicted PCS in a cohort of young athletes with SRC after controlling for sex, previous concussions, and age at the time of injury. We investigated 4 potential predictive factors and surveyed a variety of factors that were obtained from a review of the literature and that had significant empirical potential for the prediction of PCS.

\section{Methods \\ Study Design}

Institutional review board approval was obtained, and all participants (or their guardians) provided written, informed consent for research participation. Our study was a retrospective, case-control design. Participants were recruited into the Vanderbilt Sports Concussion Center (VSCC) database from high schools in the middle Tennessee area that had participated in regional neurocognitive testing programs during 2007-2013. Most high schools in this region, which represents a diversity of socioeconomic demographics, school size, and geography, participate in this program.

\section{Patient Data Identification}

Patients with PCS after SRC were identified from the VSCC database. After a child experienced head trauma, a certified athletic trainer or team physician diagnosed concussion if the examiner noted the following on-field or sideline signs or symptoms: 1) lethargy, fogginess, headache, and so on; 2) altered mental status; 3) loss of consciousness; and/or 4) amnesia. Following the recommendations of the Concussion in Sports Group consensus guidelines, we used no grading system for concussion severity. All peri-injury consultation notes, vital signs, hospitalizations, radiological images, outside medical records, and clinical communications were reviewed in our electronic medical record. ${ }^{45,46}$

Patients with PCS were defined as those experiencing postconcussion symptoms for greater than 3 months. Control patients were defined as those with documented symptom resolution by 3 weeks. The inclusion criteria were as follows: 1) the patient sustained the index concussion while playing a sport and 2) the patient was 9-18 years of age at time of injury. Exclusion criteria were as follows: 1) symptoms persisted from 3 weeks to 3 months and 2) no verifiable documentation of symptom resolution was available. Various studies diagnose PCS in patients

TABLE 1. PCS clusters

\begin{tabular}{llll}
\hline \multicolumn{1}{c}{ Somatic } & \multicolumn{1}{c}{ Cognitive } & Sleep & Emotional \\
\hline Headaches & Fatigue & Difficulty sleeping & More emotional \\
\hline Visual problems & Fogginess & Sleeping less than usual & Sadness \\
\hline Dizziness & Drowsiness & Sleeping more than usual & Nervousness \\
\hline Photophobia/phonophobia & Difficulty concentrating/remembering & & Irritability \\
\hline Nausea/vomiting & Cognitive slowing & & \\
\hline Balance problems & & & \\
\hline Numbness/tingling & & & \\
\hline
\end{tabular}


with symptoms lasting 1 month; however, we chose to adhere to the strict temporal definition in the Diagnostic and Statistical Manual of Mental Disorders, Edition 4, which states that PCS patients are symptomatic beyond 3 months. ${ }^{1,2,27,39,59}$

During 2011-2013, a total of 1116 patients were seen at VSCC. From this group, 40 patients identified as having PCS resulting from a sports-related mechanism were identified from a cohort referred to the Pediatric Neurology Clinic at Monroe Carell Jr. Children's Hospital at Vanderbilt. The first 40 patients with PCS were identified in alphabetical order and then matched by both age and sex to 2 control patients (1:2 matching) who had sustained an SRC but who had clear documentation by a trained health care provider (those with an $\mathrm{MD}, \mathrm{DO}, \mathrm{PhD}, \mathrm{PA}$, or $\mathrm{NP}$ degree) of symptom resolution, at rest and with exertion, within 3 weeks of injury.

\section{Data Collection}

From each patient's electronic medical record, we compiled provider consultation notes, radiological findings, medications prescribed, clinical communications, and scanned documentation. We collected data in 4 categories: 1) demographic variables; 2) key past medical, psychiatric, and family history; 3) acute-phase postinjury symptoms (at 0-24 hours); and 4) subacute-phase postinjury features (at 0-3 weeks). Significant stressors were noted if they represented major life events that were acknowledged by the patient or provider as possibly interfering with concussion recovery and symptomatology.

Although in a retrospective study it is difficult to independently corroborate medical, psychiatric, and family history, we used all peri-injury consultation notes, hospitalizations, outside medical records, and clinical communications available in our robust electronic medical record to confirm these variables. Most patients were queried by use of a standard health history form, affording each the opportunity to self-report medical, psychiatric, and family history. For symptoms in both phases, we looked for categorical endorsement of symptoms on the widely used Post-Concussion Symptom Scale (PCSS). ${ }^{34,36}$ However, because of variability in the format of provider documentation of symptom endorsement, we were not able to use the 0-6 scale of the PCSS; instead we assessed the categorical endorsement of a particular symptom (endorsed or not endorsed). Symptom clusters are detailed in Table 1. Total scores for endorsement of representative symptoms in each cluster were calculated. These data were compiled into a single database and analyzed. Body mass index (BMI) data were collected if they represented measurements taken within 6 months of the SRC.

\section{Statistical Analyses}

Descriptive statistics are reported as mean \pm SD for continuous variables and as frequency and proportion for categorical variables. Before performing analyses, we assessed variable distributions for normality by using histogram and Kolmogorov-Smirnov statistics. Univariate and bivariate association analyses were performed for demographic variables, presenting characteristics, and health care utilization variables to describe their distributions and assess their association with PCS, respectively. The chi-square Fisher exact test was used for categorical variables, ANOVA was used for normal continuous variables, and the Mann-Whitney U-test was used for nonparametric continuous variables. For bivariate analyses, significance was determined at a level of $\alpha=0.05$.

To identify the predictors most strongly associated with development of PCS, we used forward stepwise binary logistic regression models $\left(\mathrm{P}_{\text {in }}=0.05, \mathrm{P}_{\text {out }}=0.10\right)$. Each model was controlled, a priori, for patient age, sex, number of previous concussions, and race. Acute and subacute symptom cluster scores were entered into the model a priori according to our hypotheses, namely that the number of symptoms would be higher among PCS patients than among control patients for each of the 4 symptom clusters (somatic, cognitive, sleep, and emotional). Bivariate associations between PCS and independent variables were analyzed. Variables found to have a trend-level association $(\mathrm{p}<0.100)$ with PCS were assessed for collinearity by using the Spearman rank correlation coefficient. When collinearity was found, the variable with the weaker association with PCS, as defined as a smaller absolute correlation coefficient, was disqualified from the list of candidate predictor variables entered into the regression model. This regression model was evaluated for assumptions and aptness. Significance for the logistic regression was set at 0.01 (calculated as $\alpha=0.05 / 5$ ) via the Bonferroni continuity correction; 5 final variables were entered into the stepwise model. To generate the specificity and sensitivity data, we developed this model and then applied it retrospectively to the same data set. Statistical analyses were performed by using SPSS Statistics, version 20.0.0 (IBM Corp.).

\section{Results \\ Demographics}

Characteristics of the 2 groups are detailed in Table 2 . Several potentially confounding factors such as age ( $p$ $=0.722)$ and sex $(p=0.848)$ did not differ significantly between groups. Regarding the sport associated with the concussion, we found no significant difference $(p=0.197)$ between the 2 groups in the 5 major involved sports (football, basketball, baseball/softball, soccer, and other). The 3 most common sports categorized as "other" were equestrian sports, water sports, and lacrosse.

Neither race $(\mathrm{p}=0.134)$ nor type of insurance $(\mathrm{p}>$ 0.999) was associated with PCS. Female sex did not predict any symptom cluster (somatic, cognitive, sleep, or emotional) in either group. When analyzing BMI data measured within 6 months of injury, we found no significant difference in the percentage of children in whom PCS $\operatorname{did}(69.3 \%)$ and did not $(72.6 \%)$ develop $(\mathrm{p}=0.480)$.

\section{Medical, Psychiatric, and Family History}

One possible confounding factor that was purposely not kept constant was the number of previous concussions, because the literature indicates that previous concussions represent a major potential risk factor for $\mathrm{PCS}^{70}$ In this cohort, athletes with PCS reported having previously sustained more concussions than did controls $(\mathrm{p}=0.010)$. At 
TABLE 2. Characteristics of 120 participants

\begin{tabular}{|c|c|c|c|}
\hline Characteristic & PCS Patients $(n=40)$ & Control Patients $(n=80)$ & p Value \\
\hline \multicolumn{4}{|l|}{ Demographic } \\
\hline Age, mean (SD) & $14.9(2.1)$ & $14.8(2.0)$ & 0.722 \\
\hline Male, no. (\%) & $19(47.5)$ & $40(50.0)$ & 0.848 \\
\hline \multicolumn{4}{|l|}{ Race, no. (\%) } \\
\hline Black & $4(10.0)$ & $18(22.5)$ & \\
\hline Caucasian & $36(90.0)$ & $60(75.0)$ & \\
\hline Unknown & $0(0.0)$ & $2(2.5)$ & 0.134 \\
\hline \multicolumn{4}{|l|}{ Insurance, no. (\%) } \\
\hline Private & $32(80.0)$ & $63(78.8)$ & \\
\hline Other & $8(20.0)$ & $17(21.3)$ & $>0.999$ \\
\hline \multicolumn{4}{|l|}{ Medical history } \\
\hline Prior concussions, mean, no. (SD) & $0.9(0.7)$ & $0.4(0.7)$ & $0.041^{*}$ \\
\hline \multicolumn{4}{|l|}{ Neurological history, no. (\%) } \\
\hline Attention deficit disorder & $3(7.5)$ & $8(10.0)$ & 0.750 \\
\hline Mood disorder & $7(17.5)$ & $1(1.3)$ & $0.002^{*}$ \\
\hline Psychiatric & $4(10.0)$ & $1(1.3)$ & $0.042^{*}$ \\
\hline Migraine & $8(20.0)$ & $7(8.8)$ & 0.088 \\
\hline \multicolumn{4}{|l|}{ Family history, no. (\%) } \\
\hline Mood disorder & $8(20.0)$ & $3(3.8)$ & $0.006^{*}$ \\
\hline Psychiatric & $8(20.0)$ & $5(6.3)$ & $0.031^{*}$ \\
\hline Migraine & $14(35.0)$ & $9(11.3)$ & $0.003^{*}$ \\
\hline \multicolumn{4}{|l|}{ Acute $\&$ subacute phase of injury } \\
\hline \multicolumn{4}{|l|}{ Sport, no. (\%) } \\
\hline Football & $10(25.0)$ & $27(33.8)$ & \\
\hline Baseball/softball & $3(7.5)$ & $4(5.0)$ & \\
\hline Basketball & $5(12.5)$ & $14(17.5)$ & \\
\hline Soccer & $4(10.0)$ & $15(18.8)$ & \\
\hline Other & $18(45.0)$ & $20(25.0)$ & 0.197 \\
\hline Admitted, no. (\%) & $3(7.5)$ & $0(0.0)$ & $0.035^{*}$ \\
\hline Helmeted, no. (\%) & $11(27.5)$ & $25(31.3)$ & 0.833 \\
\hline \multicolumn{4}{|l|}{ Initial presentation, no. (\%) } \\
\hline Athletic trainer, certified & $0(0.0)$ & $1(1.2)$ & \\
\hline Clinic & $23(57.5)$ & $41(51.3)$ & \\
\hline Emergency department & $17(42.5)$ & $36(45.0)$ & \\
\hline On field & $0(0.0)$ & $1(1.3)$ & \\
\hline Outside emergency department & $0(0.0)$ & $1(1.3)$ & 0.785 \\
\hline \multicolumn{4}{|l|}{ Acute symptoms, mean score (SD) } \\
\hline Somatic cluster & $3.0(1.7)$ & $3.0(2.1)$ & 0.861 \\
\hline Cognitive cluster & $0.4(1.1)$ & $0.6(1.2)$ & 0.122 \\
\hline Sleep cluster & $0.1(0.4)$ & $0.1(0.3)$ & 0.826 \\
\hline Emotional cluster & $0.0(0.2)$ & $0.1(0.4)$ & 0.270 \\
\hline Loss of consciousness, no. (\%) & $9(22.5)$ & $17(21.3)$ & $>0.999$ \\
\hline Delayed symptoms, no. (\%) & $10(25.0)$ & $2(2.5)$ & $<0.001$ \\
\hline Neck pain, no. (\%) & $7(17.5)$ & $17(21.2)$ & 0.809 \\
\hline Amnestic, no. (\%) & $11(27.5)$ & $26(32.5)$ & 0.677 \\
\hline \multicolumn{4}{|l|}{ Subacute symptoms, mean (SD) } \\
\hline Somatic cluster score & $3.0(1.7)$ & $2.8(2.3)$ & 0.426 \\
\hline Cognitive cluster score & $1.4(1.6)$ & $1.6(1.7)$ & 0.760 \\
\hline Sleep cluster score & $0.4(0.7)$ & $0.4(0.6)$ & 0.834 \\
\hline Emotional cluster score & $0.5(1.0)$ & $0.6(0.9)$ & 0.487 \\
\hline
\end{tabular}


TABLE 2. Characteristics of 120 participants (continued)

\begin{tabular}{lccc}
\hline \multicolumn{1}{c}{ Characteristic } & PCS Patients $(\mathrm{n}=40)$ & Control Patients $(\mathrm{n}=80)$ & $\mathrm{p}$ Value \\
\hline $\begin{array}{l}\text { Acute \& subacute phase of injury (continued) } \\
\text { Pain medication use, no. (\%) }\end{array}$ & & & \\
\hline Over-the-counter & $29(72.5)$ & $48(60.0)$ & 0.227 \\
\hline Narcotics & $9(22.5)$ & $8(10.0)$ & 0.094 \\
\hline Significant stressor, no. $(\%)$ & $3(7.5)$ & $0(0.0)$ & $0.036^{*}$ \\
\hline$*$ Indicates statistical significance. & &
\end{tabular}

least 2 previous concussions had been sustained by $27.5 \%$ of PCS patients and only $7.5 \%$ of control patients. PCS was more likely to develop in athletes with history of premorbid mood disorders $(\mathrm{p}=0.002)$ and psychiatric illness $(p=0.039)$ but not migraine $(p=0.088)$. Significant stressors (close family member deaths and bullying) during SRC recovery was reported by 3 (7.5\%) PCS patients. Other PCS predictors were a family history of mood disorders $(\mathrm{p}=0.006)$ and migraine $(\mathrm{p}=0.003)$. No significant association was found between development of PCS and presence of attention deficit hyperactivity disorder or a learning disability $(\mathrm{p}=0.750)$.

\section{Acute and Subacute Symptoms}

No bivariate associations were found between acutephase symptom scores or subacute-phase symptom scores and development of PCS. Delayed symptom onset, defined as the report of being asymptomatic for at least 3 hours postinjury, was 10 times more prevalent among PCS than control patients $(25.0 \%$ vs $2.5 \%, \mathrm{p}=0.001)$. PCS was not predicted by loss of consciousness, amnesia, use of an over-the-counter pain reliever, use of a narcotic pain reliever, initial consultation with a healthcare provider, or wearing a helmet.

\section{Overall PCS Prediction Model}

Bivariate analysis identified a personal or family history of mood disorders and the presence of delayed symptoms as candidate predictor variables to be entered into the forward stepwise binary logistic regression model. For model entry, the forward stepwise logistic regression model used these candidate variables along with acute and subacute symptom cluster scores, history of mood disorders, family history of mood disorders, presence of delayed symptoms, and the acute emotional cluster. The overall model explained a significant proportion of variance in PCS development with the Nagelkerke $\mathrm{R}^{2}=0.450$ and was significant at $\mathrm{p}<0.001$ according to the model chi-square statistic. The model predicted $80.2 \%$ of correct classifications overall with a sensitivity of $55.0 \%$ and a specificity of $92.6 \%$. Independently, a history of mood disorders was associated with increased risk for PCS development (relative risk 17.9, 95\% CI 2.9-113.0, $\mathrm{p}=0.002$ ), along with presence of delayed symptoms (relative risk 20.7, 95\% CI 3.2-132.0, $\mathrm{p}=0.001$ ). The acute emotional cluster scores were not associated with a decreased likelihood of PCS when the Bonferroni-corrected significance level of $\alpha=0.01$ was used. Results of the final logistic regression model are detailed in Table 3.

\section{Discussion}

In this case-control study of risk factors for PCS among young athletes, risk for PCS was higher among those with an individual or family history of preinjury psychiatric illness and migraines. Other predictors were an increasing number of previous concussions and delay in symptom onset. Findings from this study expand the growing list of known risk factors for PCS identified in our literature review (Table 4).

\section{Demographics}

We found that for this cohort, insurance status did not predict PCS. Although evidence suggests that high family stress in higher-functioning families with greater environmental resources may predict PCS in children with mTBI, our data do not indicate an effect of having private insurance over state or federally funded programs. ${ }^{56,69}$

We also did not find an association between race and development of PCS. This finding was notable because children of minority race are significantly more likely to experience underdiagnosis; undertreatment; and conditions like asthma, attention deficit hyperactivity disorder, and learning difficulties. . $^{14,20,21,54,67}$ In addition, a prospective, observational study of 71 adults with mTBI who sought care at an emergency department found that although patients were discharged with instructions to follow up with a primary care provider within 1-2 weeks, African Americans were less likely to do so $(\mathrm{OR}=0.36,95 \% \mathrm{CI}$ $0.13-0.99) .{ }^{4}$ In that study, patients without a primary care provider were assigned one, which introduced the patient to an unknown physician. Also in that study, confidence intervals were remarkably wide. Because that study ex-

TABLE 3. Final stepwise logistic regression model assessing predictors of PCS after SRC

\begin{tabular}{lccc}
\hline \multicolumn{4}{c}{ Predictor of PCS } \\
\hline \multicolumn{1}{c}{ Independent Variable } & $\operatorname{Exp}(\beta)$ & $95 \% \mathrm{Cl}$ & $\mathrm{p}$ Value \\
\hline Constant & 0.31 & & 0.558 \\
\hline Age & 0.97 & $0.78-1.21$ & 0.806 \\
\hline Male sex & 0.78 & $0.30-2.02$ & 0.606 \\
\hline No. of previous concussions & 1.78 & $1.12-2.84$ & $0.016^{*}$ \\
\hline Mood disorder & 17.94 & $2.85-112.95$ & $0.002^{*}$ \\
\hline Family history & 3.11 & $1.14-8.45$ & 0.026 \\
\hline Delayed symptoms & 20.69 & $3.24-131.97$ & $0.001^{*}$ \\
\hline Acute emotional cluster & 0.04 & $0.00-6.33$ & $0.023^{*}$ \\
\hline
\end{tabular}

* Indicates statistical significance. 


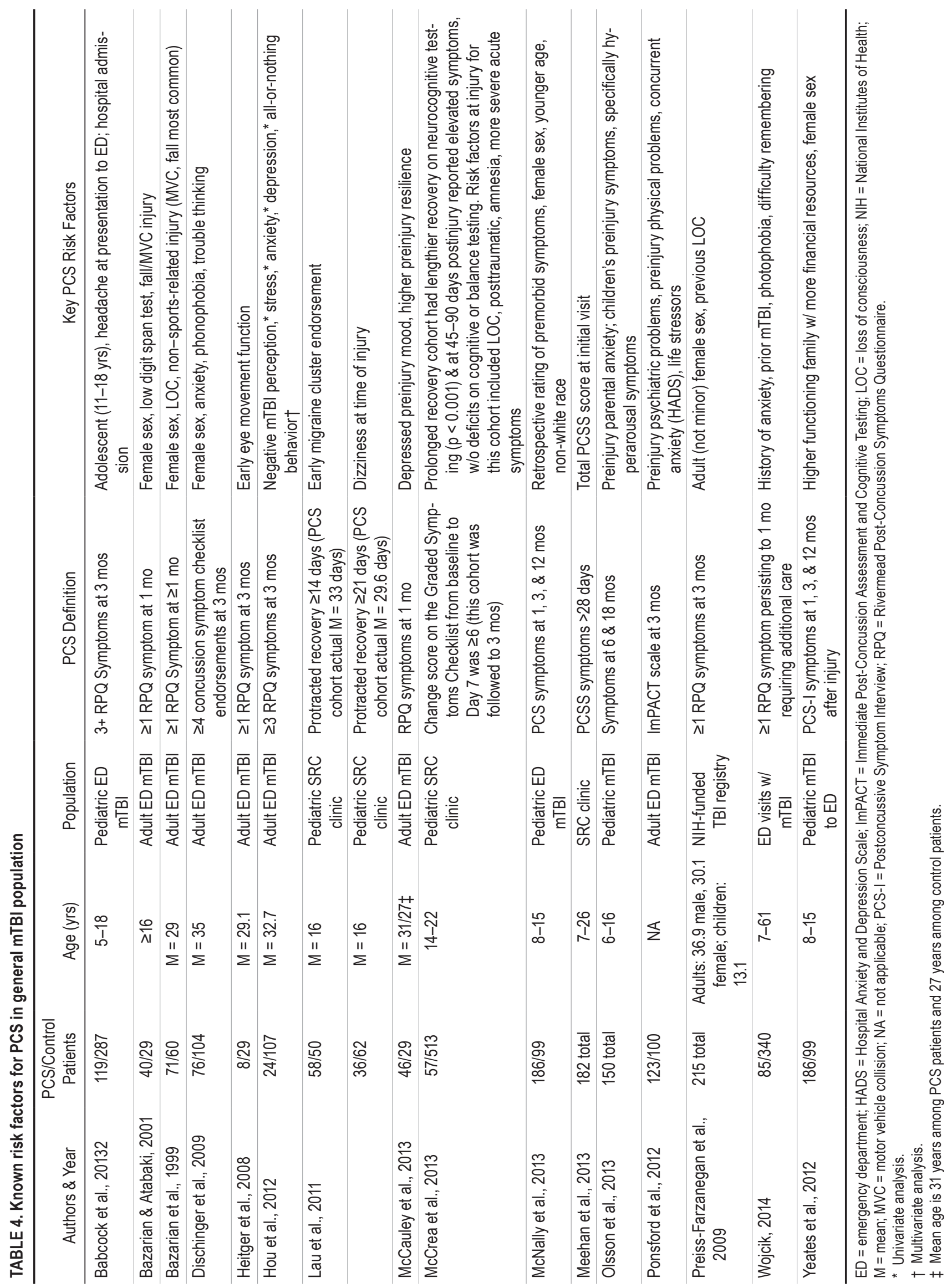


amined adults with all forms of mTBI, it is not clear if this trend would be expected for children with SRC.

\section{Medical, Psychiatric, and Family History}

We found that PCS was more likely to develop after concussion in young athletes with preexisting mood disorders or psychiatric illness. These findings corroborate those of studies of general mTBI in older patients, that PCS is more likely to develop after mTBI in adults experiencing depression, anxiety, and/or life stressors. ${ }^{16,29,41,57,68}$ However, whether this finding applies to young athletes with SRC remains unclear. One prospective study of 130 children 6-15 years of age who received care for mTBI at 2 emergency departments were followed up at 1 week and 3 months after injury. ${ }^{59}$ Concussions were sustained mostly from falls (34\%), cycling accidents (21\%), and sports $(24 \%)$. Of the $85 \%$ examined during a 3-month follow-up visit, PCS had developed in 17\%. Those with PCS were more likely to have had a previous head injury $(\mathrm{p}<$ $0.001)$, learning difficulties $(\mathrm{p}=0.02)$, psychiatric illness $(\mathrm{p}=0.02)$, or premorbid family stressors $(\mathrm{p}<0.001){ }^{58}$ One major limitation of the aforementioned study was that postinjury behavior and symptoms were obtained from the parent or guardian, not the child. If parental stress modifies endorsement of PCS symptoms, it is unclear if these data truly reflect the child's symptoms. ${ }^{56}$

Prevalent among our cohort of young athletes with PCS after concussion were family histories of mood disorders $(\mathrm{p}=0.006)$, other psychiatric illness $(\mathrm{p}=0.031)$, and migraine $(p=0.003)$. It is worth mentioning that migraine histories were determined on the basis of self-report of a migraine disorder or chronic headache syndrome. For example, many patients reported that siblings at times experienced "headaches." However, we only included patients who self-reported either a significant chronic headache syndrome or migraine disorder.

This higher prevalence of mood disorders and psychiatric illness is consistent with previous findings that preinjury parental anxiety and family and life stressors predict protracted mTBI recovery in children. ${ }^{56,58}$ These findings emphasize the value of addressing concussion recovery specifically in children and adolescents, who must recover within the context of complex modifiers like parental stressors. It is difficult to say whether these proposed modifiers are genetic, environmental, or both. True manifestations of PCS can be difficult to distinguish from symptoms of primary disorders of depression, anxiety, and migraine. ${ }^{10,48}$ Baseline health and psychiatric status of both the child and the primary caregivers should be considered with regard to symptom reporting and expectations regarding recovery.

\section{Acute and Subacute Symptoms}

We did not find that loss of consciousness, amnesia, or any symptom cluster predicted PCS. This finding probably results from the fact that these risk factors have been identified in youth cohorts that included all forms of mTBI, not just those resulting from sporting activities. These more severe forms of impact include motor vehicle collisions, falls, and assaults. However, one unexpected finding was that in our cohort, PCS was significantly more likely to de- velop in athletes who endorsed delayed symptoms (onset $>$ 3 hours postinjury) ( $<<0.001)$. A common scenario was the athlete continuing to play after the significant hit and only noticing symptoms well after the game. The implication of this finding is that athletes who do not experience symptoms immediately might not be removed from play at the actual time of injury. This implication is especially true given that loss of consciousness and amnesia, obvious and severe manifestations of SRC, were rare in our cohort and in the literature for this population. ${ }^{49}$ By remaining in play, these young athletes may then experience second hits, exposing their already injured brain to additional insults. The interaction between delayed symptoms and development of PCS is complex and warrants further study.

Second hits in a short time frame are significant for 2 reasons. First, the American Academy of Pediatrics, the American Medical Society for Sports Medicine, the American College of Sports Medicine, the Concussion in Sports Group, and the American Academy of Neurology have all issued statements instructing both physical rest and cognitive rest immediately after SRC in a young person, based on evidence that rest expedites symptom-free recovery. ${ }^{22,25,26,28,45}$ However, although recommended by these groups, the exact nature and quantifiable benefit of quality physical and cognitive rest remains controversial. ${ }^{12,54,55,67}$ Second, decreasing the time between repeat concussions is an independent risk factor for protracted recovery in mice and children. ${ }^{52}$ Beckwith et al. and Duhaime et al. highlighted the difficulty of SRC diagnosis because of variability in on-field symptoms, an athlete's willingness to report, and the potential for delayed symptom onset, seen in up to $50 \%$ of a sample of college football players with SRC. ${ }^{8,17}$ Furthermore, subconcussive impacts are increasingly being recognized as having potentially negative long-term cognitive effects for those who play contact sports. Talavage et al. reported that for 11 male football players who had no clinical concussion symptoms over the course of 1 season, neurocognitive testing indicated development of significant deficits, highlighting the risks and ramifications of repetitive, subconcussive impacts..$^{65}$ Another study by Duhaime et al. used instrumented helmets to follow 450 college football and ice hockey teams. Although 486,594 head impacts were recorded during the study period, for one-third of all diagnosed concussions, the contact event was not clinically apparent to officials or by report from the athlete. ${ }^{32}$

In another prospective study of 1208 college football players wearing instrumented helmets, concussions were more likely to be diagnosed immediately after impacts with the highest kinematic measures. These more forceful hits resulted in these same players being removed from play immediately. However, those players for whom diagnosis was delayed were more likely to continue to play and have a higher number of recorded, subconcussive, repeated head impacts. ${ }^{8}$ These findings could potentially explain why young athletes with SRC in this study in whom PCS later developed were more likely to report delayed symptom onset; if symptoms were delayed, diagnosis would be delayed, play would continue with risk for repeated impacts, and beneficial physical rest and cognitive rest could not begin. Although each of these studies focuses on older, 
collegiate athletes, there is no plausible reason to think that the younger athletes in our study are less prone to these same repetitive, subconcussive impacts.

All patients included in this study experienced a "big impact" during play, based on the medical record history provided by the patient or a family member. We offer only serial hits or lack of rest as possible explanations. However, other possibilities could explain the connection between delayed symptoms and PCS. The high prevalence of behavioral health problems in the PCS cohort may also influence the onset of symptoms. Regardless, these preliminary data argue for prospective evaluation of serial hits and delayed symptom onset in larger samples.

\section{Limitations}

The lack of predictive symptom clusters could be explained by a limitation in our study, which precluded the use of anything beyond categorical variables for endorsement of a given symptom. Although we used symptoms present on the PCSS, because of variability in formats of symptom documentation by providers, a 0-6 scale was impossible to use consistently for patients in this retrospective case-control study. Widely used standard forms like the Rivermead Post-Concussion Symptoms Questionnaire and the PCSS have severity of symptom scales, which allow more nuance for the endorsement of a given symptom. ${ }^{13,32,34}$ However, these forms were not consistently used by clinicians involved with patients in our study. Our observed variation in symptom documentation used by providers is troubling and is probably a source of significant variability in the literature.

We also do not know what the scores on such a scale would have been for patients in this cohort before an SRC. This baseline information would be useful, given the relative nonspecificity of postconcussion symptoms. This finding speaks to the urgent need for consistent provider use of a symptom scale to allow quality continuity of care between emergency departments, primary care physicians, sports medicine providers, and other specialists. Additionally, it is unclear if symptom scales currently in use are generalizable to populations at increased risk for PCS, like those with mood disorders, migraine histories, or numerous previous concussions. Both the retrospective nature of our study and its location in only 1 region of the country limit the generalizability of our results.

\section{Future Directions}

The lack of verified biological explanations for the nonspecific symptoms seen with PCS has led many to question its legitimacy as a disease entity. ${ }^{18,48}$ As a result, many have recently focused efforts on identifying biomarkers that might predict or be hallmarks of PCS development. Noting that the G(-1019) allele of HTRIA is associated with major depression and suicide, a team led by Smyth et al. ${ }^{64}$ examined the prevalence of the G(-1019) allele in children with mTBI. In their cross-sectional study of 47 symptomatic children who experienced postconcussive symptoms for 7 or more days, the $\mathrm{G}$ allelic frequency and genotypic frequency for HTRIA polymorphisms was similar to that among controls. ${ }^{64}$ In another study, S100B, an astroglial calcium-channel binding protein was found to be elevated after mild to severe TBI. ${ }^{1}$ S100B is also highly correlated with abnormal cranial CT scans of mTBI patients; sensitivity is remarkable $(90 \%-100 \%) .{ }^{1,2}$ A retrospective analysis of 76 children with mTBI measured S100B levels immediately after mTBI; however, no association was found between serum levels of S100B at this time and later development of PCS. ${ }^{1}$ Cleaved tau protein, although elevated in patients after intracranial injury and correlated with functional outcomes after moderate to severe TBI, is also not detected more often in adult patients with PCS than in those without. , $, 931,39$ However, because each of these studies in this developing field focused on head injury of adults, the current generalizability to SRC in youth remains unclear.

\section{Conclusions}

We present demographic and clinical evidence highlighting the value of recognizing the unique nature of SRC in young athletes. Children and adolescents who either themselves have, or have family members with, mood disorders, psychiatric illness, or migraines may occupy a disproportionate share of the "miserable minority" of PCS sufferers. ${ }^{60,61}$ Our study also demonstrates that delayed symptom onset may be more prevalent among young athletes with PCS; the implications of this delay and how this affects decisions surrounding removal from play should be investigated more thoroughly in large prospective cohorts.

\section{References}

1. Babcock L, Byczkowski T, Wade SL, Ho M, Bazarian JJ: Inability of S100B to predict postconcussion syndrome in children who present to the emergency department with mild traumatic brain injury: a brief report. Pediatr Emerg Care 29:458-461, 2013

2. Babcock L, Byczkowski T, Wade SL, Ho M, Mookerjee S, Bazarian JJ: Predicting postconcussion syndrome after mild traumatic brain injury in children and adolescents who present to the emergency department. JAMA Pediatr 167:156161,2013

3. Barlow M, Schlabach D, Peiffer J, Cook C: Differences in change scores and the predictive validity of three commonly used measures following concussion in the middle school and high school aged population. Int J Sports Phys Ther 6:150-157, 2011

4. Bazarian J, Hartman M, Delahunta E: Minor head injury: predicting follow-up after discharge from the emergency department. Brain Inj 14:285-294, 2000

5. Bazarian JJ, Atabaki S: Predicting postconcussion syndrome after minor traumatic brain injury. Acad Emerg Med 8:788795, 2001

6. Bazarian JJ, Wong T, Harris M, Leahey N, Mookerjee S, Dombovy M: Epidemiology and predictors of post-concussive syndrome after minor head injury in an emergency population. Brain Inj 13:173-189, 1999

7. Bazarian JJ, Zemlan FP, Mookerjee S, Stigbrand T: Serum S-100B and cleaved-tau are poor predictors of long-term outcome after mild traumatic brain injury. Brain Inj 20:759765, 2006

8. Beckwith JG, Greenwald RM, Chu JJ, Crisco JJ, Rowson S, Duma SM, et al: Head impact exposure sustained by football players on days of diagnosed concussion. Med Sci Sports Exerc 45:737-746, 2013

9. Begaz T, Kyriacou DN, Segal J, Bazarian JJ: Serum biochemical markers for post-concussion syndrome in patients with 
mild traumatic brain injury. J Neurotrauma 23:1201-1210, 2006

10. Blume H, Hawash K: Subacute concussion-related symptoms and postconcussion syndrome in pediatrics. Curr Opin Pediatr 24:724-730, 2012

11. Browne GJ, Lam LT: Concussive head injury in children and adolescents related to sports and other leisure physical activities. Br J Sports Med 40:163-168, 2006

12. Carson JD, Lawrence DW, Kraft SA, Garel A, Snow CL, Chatterjee A, et al: Premature return to play and return to learn after a sport-related concussion: physician's chart review. Can Fam Physician 60:e310-e315, 2014

13. Chen JK, Johnston KM, Collie A, McCrory P, Ptito A: A validation of the post concussion symptom scale in the assessment of complex concussion using cognitive testing and functional MRI. J Neurol Neurosurg Psychiatry 78:12311238,2007

14. Coker TR, Elliott MN, Kataoka S, Schwebel DC, Mrug S, Grunbaum JA, et al: Racial/ethnic disparities in the mental health care utilization of fifth grade children. Acad Pediatr 9:89-96, 2009

15. Collins MW, Iverson GL, Lovell MR, McKeag DB, Norwig $\mathrm{J}$, Maroon J: On-field predictors of neuropsychological and symptom deficit following sports-related concussion. Clin J Sport Med 13:222-229, 2003

16. Dischinger PC, Ryb GE, Kufera JA, Auman KM: Early predictors of postconcussive syndrome in a population of trauma patients with mild traumatic brain injury. J Trauma 66:289-297, 2009

17. Duhaime AC, Beckwith JG, Maerlender AC, McAllister TW, Crisco JJ, Duma SM, et al: Spectrum of acute clinical characteristics of diagnosed concussions in college athletes wearing instrumented helmets. Clinical article. J Neurosurg 117:1092-1099, 2012

18. Evans RW: Persistent post-traumatic headache, postconcussion syndrome, and whiplash injuries: the evidence for a non-traumatic basis with an historical review. Headache 50:716-724, 2010

19. Fazio VC, Lovell MR, Pardini JE, Collins MW: The relation between post concussion symptoms and neurocognitive performance in concussed athletes. NeuroRehabilitation 22:207-216, 2007

20. Flores G, Denne SC, Bauer AJ, Cabana MD, Cheng TL, Notterman DA: Technical report-racial and ethnic disparities in the health and health care of children. Pediatrics 125:e979e1020, 2010

21. Flores G, Tomany-Korman SC: Racial and ethnic disparities in medical and dental health, access to care, and use of services in US children. Pediatrics 121:e286-e298, 2008

22. Giza CC, Kutcher JS, Ashwal S, Barth J, Getchius TSD, Gioia GA, et al: Summary of evidence-based guideline update: evaluation and management of concussion in sports. Report of the Guideline Development Subcommittee of the American Academy of Neurology. Neurology 80:2250-2257, 2013

23. Guskiewicz KM, McCrea M, Marshall SW, Cantu RC, Randolph C, Barr W, et al: Cumulative effects associated with recurrent concussion in collegiate football players: the NCAA Concussion Study. JAMA 290:2549-2555, 2003

24. Guskiewicz KM, Ross SE, Marshall SW: Postural stability and neuropsychological deficits after concussion in collegiate athletes. J Athl Train 36:263-273, 2001

25. Halstead ME, McAvoy K, Devore CD, Carl R, Lee M, Logan $\mathrm{K}$ : Returning to learning following a concussion. Pediatrics 132:948-957, 2013

26. Harmon KG, Drezner JA, Gammons M, Guskiewicz KM, Halstead M, Herring SA, et al: American Medical Society for Sports Medicine position statement: concussion in sport. Br J Sports Med 47:15-26, 2013
27. Heitger MH, Jones RD, Anderson TJ: A new approach to predicting postconcussion syndrome after mild traumatic brain injury based upon eye movement function. Conf Proc IEEE Eng Med Biol Soc 2008:3570-3573, 2008

28. Herring SA, Cantu RC, Guskiewicz KM, Putukian M, Kibler WB, Bergfeld JA, et al: Concussion (mild traumatic brain injury) and the team physician: a consensus statement-2011 update. Med Sci Sports Exerc 43:2412-2422, 2011

29. Hou R, Moss-Morris R, Peveler R, Mogg K, Bradley BP, Belli A: When a minor head injury results in enduring symptoms: a prospective investigation of risk factors for postconcussional syndrome after mild traumatic brain injury. $\mathbf{J}$ Neurol Neurosurg Psychiatry 83:217-223, 2012

30. Iverson GL, Brooks BL, Collins MW, Lovell MR: Tracking neuropsychological recovery following concussion in sport. Brain Inj 20:245-252, 2006

31. Kavalci C, Pekdemir M, Durukan P, Ilhan N, Yildiz M, Serhatlioglu S, et al: The value of serum tau protein for the diagnosis of intracranial injury in minor head trauma. Am J Emerg Med 25:391-395, 2007

32. King NS, Crawford S, Wenden FJ, Moss NE, Wade DT: The Rivermead Post Concussion Symptoms Questionnaire: a measure of symptoms commonly experienced after head injury and its reliability. J Neurol 242:587-592, 1995

33. Kontos AP, Elbin RJ, Lau B, Simensky S, Freund B, French $\mathrm{J}$, et al: Posttraumatic migraine as a predictor of recovery and cognitive impairment after sport-related concussion. Am J Sports Med 41:1497-1504, 2013

34. Kontos AP, Elbin RJ, Schatz P, Covassin T, Henry L, Pardini $\mathrm{J}$, et al: A revised factor structure for the post-concussion symptom scale: baseline and postconcussion factors. Am J Sports Med 40:2375-2384, 2012

35. Lau B, Lovell MR, Collins MW, Pardini J: Neurocognitive and symptom predictors of recovery in high school athletes. Clin J Sport Med 19:216-221, 2009

36. Lau BC, Collins MW, Lovell MR: Cutoff scores in neurocognitive testing and symptom clusters that predict protracted recovery from concussions in high school athletes. Neurosurgery 70:371-379, 2012

37. Lau BC, Collins MW, Lovell MR: Sensitivity and specificity of subacute computerized neurocognitive testing and symptom evaluation in predicting outcomes after sports-related concussion. Am J Sports Med 39:1209-1216, 2011

38. Lovell MR, Collins MW, Iverson GL, Field M, Maroon JC, Cantu R, et al: Recovery from mild concussion in high school athletes. J Neurosurg 98:296-301, 2003

39. Ma M, Lindsell CJ, Rosenberry CM, Shaw GJ, Zemlan FP: Serum cleaved tau does not predict postconcussion syndrome after mild traumatic brain injury. Am J Emerg Med 26:763768, 2008

40. Makdissi M, Cantu RC, Johnston KM, McCrory P, Meeuwisse WH: The difficult concussion patient: what is the best approach to investigation and management of persistent $(>10$ days) postconcussive symptoms? Br J Sports Med 47:308313,2013

41. McCauley SR, Wilde EA, Miller ER, Frisby ML, Garza HM, Varghese R, et al: Preinjury resilience and mood as predictors of early outcome following mild traumatic brain injury. $\mathbf{J}$ Neurotrauma 30:642-652, 2013

42. McCrea M, Barr WB, Guskiewicz K, Randolph C, Marshall SW, Cantu R, et al: Standard regression-based methods for measuring recovery after sport-related concussion. J Int Neuropsychol Soc 11:58-69, 2005

43. McCrea M, Guskiewicz K, Randolph C, Barr WB, Hammeke TA, Marshall SW, et al: Incidence, clinical course, and predictors of prolonged recovery time following sport-related concussion in high school and college athletes. J Int Neuropsychol Soc 19:22-33, 2013

44. McCrea M, Guskiewicz KM, Marshall SW, Barr W, Ran- 
dolph C, Cantu RC, et al: Acute effects and recovery time following concussion in collegiate football players: the NCAA Concussion Study. JAMA 290:2556-2563, 2003

45. McCrory P, Meeuwisse W, Aubry M, Cantu B, Dvorak J, Echemendia RJ, et al: Consensus statement on concussion in sport-the 4th International Conference on Concussion in Sport held in Zurich, November 2012. Clin J Sport Med 23:89-117, 2013

46. McCrory P, Meeuwisse W, Johnston K, Dvorak J, Aubry M, Molloy M, et al: Consensus statement on Concussion in Sport-the 3rd International Conference on Concussion in Sport held in Zurich, November 2008. J Sci Med Sport 12:340-351, 2009

47. McNally KA, Bangert B, Dietrich A, Nuss K, Rusin J, Wright $\mathrm{M}$, et al: Injury versus noninjury factors as predictors of postconcussive symptoms following mild traumatic brain injury in children. Neuropsychology 27:1-12, 2013

48. Meares S, Shores EA, Taylor AJ, Batchelor J, Bryant RA, Baguley IJ, et al: Mild traumatic brain injury does not predict acute postconcussion syndrome. J Neurol Neurosurg Psychiatry 79:300-306, 2008

49. Meehan WP III, d'Hemecourt P, Comstock RD: High school concussions in the 2008-2009 academic year: mechanism, symptoms, and management. Am J Sports Med 38:24052409, 2010

50. Meehan WP III, Mannix RC, Stracciolini A, Elbin RJ, Collins MW: Symptom severity predicts prolonged recovery after sport-related concussion, but age and amnesia do not. J Pediatr 163:721-725, 2013

51. Meehan WP III, Taylor AM, Proctor M: The pediatric athlete: younger athletes with sport-related concussion. Clin Sports Med 30:133-144, x, 2011

52. Meehan WP III, Zhang J, Mannix R, Whalen MJ: Increasing recovery time between injuries improves cognitive outcome after repetitive mild concussive brain injuries in mice. Neurosurgery 71:885-891, 2012

53. Mihalik JP, Stump JE, Collins MW, Lovell MR, Field M, Maroon JC: Posttraumatic migraine characteristics in athletes following sports-related concussion. J Neurosurg 102: 850-855, 2005

54. Moser RS, Glatts C, Schatz P: Efficacy of immediate and delayed cognitive and physical rest for treatment of sportsrelated concussion. J Pediatr 161:922-926, 2012

55. Moser RS, Schatz P: A case for mental and physical rest in youth sports concussion: it's never too late. Front Neurol 3:171, 2012

56. Olsson KA, Lloyd OT, Lebrocque RM, McKinlay L, Anderson VA, Kenardy JA: Predictors of child post-concussion symptoms at 6 and 18 months following mild traumatic brain injury. Brain Inj 27:145-157, 2013

57. Ponsford J, Cameron P, Fitzgerald M, Grant M, MikockaWalus A, Schönberger M: Predictors of postconcussive symptoms 3 months after mild traumatic brain injury. Neuropsychology 26:304-313, 2012

58. Ponsford J, Willmott C, Rothwell A, Cameron P, Ayton G, Nelms R, et al: Cognitive and behavioral outcome following mild traumatic head injury in children. J Head Trauma Rehabil 14:360-372, 1999

59. Preiss-Farzanegan SJ, Chapman B, Wong TM, Wu J, Bazar- ian JJ: The relationship between gender and postconcussion symptoms after sport-related mild traumatic brain injury. PM R 1:245-253, 2009

60. Rohling ML, Larrabee GJ, Millis SR: The "miserable minority" following mild traumatic brain injury: who are they and do meta-analyses hide them? Clin Neuropsychol 26:197213, 2012

61. Ruff RM, Camenzuli L, Mueller J: Miserable minority: emotional risk factors that influence the outcome of a mild traumatic brain injury. Brain Inj 10:551-565, 1996

62. Schatz P, Moser RS, Covassin T, Karpf R: Early indicators of enduring symptoms in high school athletes with multiple previous concussions. Neurosurgery 68:1562-1567, 2011

63. Scopaz KA, Hatzenbuehler JR: Risk modifiers for concussion and prolonged recovery. Sports Health 5:537-541, 2013

64. Smyth K, Sandhu SS, Crawford S, Dewey D, Parboosingh J, Barlow KM: The role of serotonin receptor alleles and environmental stressors in the development of post-concussive symptoms after pediatric mild traumatic brain injury. Dev Med Child Neurol 56:73-77, 2014

65. Talavage TM, Nauman EA, Breedlove EL, Yoruk U, Dye AE, Morigaki KE, et al: Functionally-detected cognitive impairment in high school football players without clinicallydiagnosed concussion. J Neurotrauma 31:327-338, 2014

66. Taylor HG, Dietrich A, Nuss K, Wright M, Rusin J, Bangert $\mathrm{B}$, et al: Post-concussive symptoms in children with mild traumatic brain injury. Neuropsychology 24:148-159, 2010

67. Upchurch C, Morgan CD, Umfress A, Yang G, Riederer MF: Discharge instructions for youth sports-related concussions in the emergency department, 2004 to 2012. Clin J Sport Med [epub ahead of print], 2014

68. Wojcik SM: Predicting mild traumatic brain injury patients at risk of persistent symptoms in the emergency department. Brain Inj 28:422-430, 2014

69. Yeates KO, Taylor HG, Rusin J, Bangert B, Dietrich A, Nuss $\mathrm{K}$, et al: Premorbid child and family functioning as predictors of post-concussive symptoms in children with mild traumatic brain injuries. Int J Dev Neurosci 30:231-237, 2012

70. Zemek RL, Farion KJ, Sampson M, McGahern C: Prognosticators of persistent symptoms following pediatric concussion: a systematic review. JAMA Pediatr 167:259-265, 2013

\section{Author Contributions}

Conception and design: Zuckerman, Morgan, King, Beiard. Acquisition of data: Morgan. Analysis and interpretation of data: Zuckerman, Morgan. Drafting the article: Morgan. Critically revising the article: Zuckerman, Morgan, King, Beaird, Sills, Solomon. Reviewed submitted version of manuscript: all authors. Statistical analysis: Zuckerman, Morgan. Administrative/techni$\mathrm{cal} /$ material support: all authors. Study supervision: Zuckerman, Morgan, Sills, Solomon.

\section{Correspondence}

Scott L. Zuckerman, Vanderbilt Department of Neurological Surgery, 1211 Medical Center Dr., Medical Center North T-4224, Nashville, TN 37212. email: scott.zuckerman@vanderbilt.edu. 